Article

\title{
Biodegradable and Antimicrobial PLA-OLA Blends Containing Chitosan-Mediated Silver Nanoparticles with Shape Memory Properties for Potential Medical Applications
}

\author{
Agueda Sonseca ${ }^{1,2, *,+}$, Salim Madani ${ }^{3}$, Alexandra Muñoz-Bonilla ${ }^{1,2}$ (D), \\ Marta Fernández-García 1,2 (D), Laura Peponi 1,2, Adrián Leonés 1,2, Gema Rodríguez ${ }^{1,2}$, \\ Coro Echeverría ${ }^{1,2}$ and Daniel López ${ }^{1,2, * \mathbb{D}}$ \\ 1 MacroEng Group, Instituto de Ciencia y Tecnología de Polímeros, ICTP-CSIC, C/Juan de la Cierva 3, \\ 28006 Madrid, Spain; sbonilla@ictp.csic.es (A.M.-B.); martafg@ictp.csic.es (M.F.-G.); \\ lpeponi@ictp.csic.es (L.P.); aleones@ictp.csic.es (A.L.); gema@ictp.csic.es (G.R.); \\ cecheverria@ictp.csic.es (C.E.) \\ 2 Interdisciplinary Plataform for "Sustainable Plastics towards a Circular Economy" (SUSPLAST-CSIC), \\ 28006 Madrid, Spain \\ 3 Laboratory of Applied Biochemistry, Department of Biology, Faculty of Sciences, University Ferhat Abbas, \\ Setif 19000, Algeria; madanisalim79@gmail.com \\ * Correspondence: agsonol@posgrado.upv.es (A.S.); daniel.l.g@csic.es (D.L.); Tel.: +34-915622900 (D.L.) \\ † Current address: Instituto de Tecnología de Materiales, Universitat Politècnica de València (UPV), \\ Camino de Vera s/n, 46022 Valencia, Spain.
}

Received: 13 May 2020; Accepted: 27 May 2020; Published: 30 May 2020

\begin{abstract}
To use shape memory materials based on poly (lactic acid) (PLA) for medical applications is essential to tune their transition temperature $\left(T_{\text {trans }}\right)$ near to the human body temperature. In this study, the combination of lactic acid oligomer (OLA), acting as a plasticizer, together with chitosan-mediated silver nanoparticles (AgCH-NPs) to create PLA matrices is studied to obtain functional shape memory polymers for potential medical applications. PLA/OLA nanocomposites containing different amounts of $\mathrm{AgCH}-\mathrm{NPs}$ were obtained and profusely characterized relating their structure with their antimicrobial and shape memory performances. Nanocomposites exhibited shape memory responses at the temperature of interest (near physiological one), as well as excellent shape memory responses, shorter recovery times and higher recovery ratios (over 100\%) when compared to neat materials. Moreover, antibacterial activity tests confirmed biocidal activity; therefore, these functional polymer nanocomposites with shape memory, degradability and biocidal activity show great potential for soft actuation applications in the medical field.
\end{abstract}

Keywords: poly (lactic acid); oligomeric lactic acid; eco-friendly silver nanoparticles; shape memory properties; antimicrobial activity; biomedical

\section{Introduction}

The use of shape memory polymers (SMP) for the development of active medical devices is perhaps the most promising and attractive area of application for these materials. They are potential candidates for stimuli-sensitive appliances, such as self-tightening and anchoring sutures/staples, surgical fasteners, orthopedic fixations and self-expandable vascular stents and implants, among others [1-3], with applicability in minimally invasive surgery. In this sense, these materials can be located in the body in a temporary and compressed/pre-deformed geometry through a small incision, to achieve their final/original and desired shape when heated to above the melting or glass transition 
temperature, causing less surgical stress. Additionally, biodegradable polymers with shape memory activation temperatures around body temperature are preferred for these types of implants, as they will cause less surgical stress and can degrade after a specific period of time, avoiding the need for their surgical removal. The activation temperature, commonly named $T_{\text {trans, }}$ can be the melting temperature, $\mathrm{T}_{\mathrm{m}}$, of the crystalline phase of the polymer or the glass transition temperature, $\mathrm{T}_{\mathrm{g}}$, depending on the nature of the polymer. Thus, in order to implement a shape memory polymeric system for applications in medicine, it is necessary to tailor its mechanical and thermal properties to fall into the desired range, which is not easily achievable.

Poly (lactic acid) (PLA) is a thermoplastic polymer that has found wide applications in the area of biomedicine in the past three decades, thanks to its good mechanical strength (pure PLLA, elastic modulus, $\mathrm{E}=3-4 \mathrm{GPa}$; tensile strength $=50-70 \mathrm{MPa}$ ), degradability, biocompatibility and non-toxicity, as well as a good thermal shape memory performance around $60{ }^{\circ} \mathrm{C}$ and its $\mathrm{T}_{\mathrm{g}}$ [4]. In spite of its strengths, PLA possesses well-known limitations such as its relatively poor processability, high stiffness and crystallinity, as well as its low elongation at break $(\varepsilon=2-10 \%)$ compared with other commercially available polymers of medical grade [4,5]. Moreover, from a shape memory point of view, its $T_{g}$ is well above the body temperature, which limits its direct application and the exploitation of such an interesting ability when creating a medical device (PDLA, $\mathrm{T}_{\mathrm{g}}=50-54{ }^{\circ} \mathrm{C} ; \mathrm{PLLA}, \mathrm{T}_{\mathrm{g}}=57-60{ }^{\circ} \mathrm{C}$ ) [5]. In this sense, it is important to highlight that the SMP research of today should overcome the limitations of SMPs for tailored practical applications such as biomedical uses, especially when involving potential materials as PLA. Therefore, numerous strategies have been explored in order to tune the properties of PLA for specific applications, including copolymerization [6] and blending [7]. The first strategy is usually used to enhance the glassy state elasticity of PLA through the incorporation of an amorphous elastic phase with a low $\mathrm{T}_{\mathrm{g}}$ to form a copolymer [8,9], which usually results in complex structures and a successful balance of shape memory performance and mechanical/thermal properties is not always reached $[10,11]$. Therefore, physical blending, either with miscible or immiscible components, is considered as a much more practical and economic way to modulate the properties of PLA [12-14]. Considering that, and taking advantage of the intrinsic compatibility among PLA and oligomers such as lactic acid oligomers (OLA), due to their similar chemical structure, we used OLA as a plasticizer for triggering the activation temperature $\left(T_{\text {trans }}\right)$ of the shape memory effect, as well as the thermal and mechanical properties of PLA. We have previously studied different PLA/OLA formulations and processed them by electrospinning, being able to control the $\mathrm{T}_{\mathrm{g}}$ and the moduli (loss and storage) in the ranges of $21-60{ }^{\circ} \mathrm{C}$ and $30-91 \mathrm{MPa}$, respectively [15]. Therefore, we were able to tailor the $\mathrm{T}_{\mathrm{g}}$ of the system to fall into the range of operating temperatures useful for medical applications $\left(\mathrm{T}_{\mathrm{g}}=40-45^{\circ} \mathrm{C}\right)$ and, thus, allow the shape memory effect of the PLA to be activated by body heat or a temperature slightly above body heat for samples containing 20-30 wt.\% of OLA.

When using a polymeric material in a medical field, bacterial infection usually needs to be considered as, statistically, it causes half of all hospital infections. More importantly, the biocompatibility of SMPs can be limited due to residues of microorganisms even prior to sterilization. Although shape memory polymers have been largely studied for creating parts of biomedical devices, the introduction of antibacterial activity into these polymeric systems remains an important task and has been mainly limited to non-degradable shape memory polyurethane materials. Furthermore, the limitation of microorganism growth on SMP systems must be addressed. Bionanocomposites represent an inspiring route for creating new and innovative medical materials, and silver nanoparticles (AgNPs) have been reported to bring improvements in the mechanical properties of dental materials [16] and, more interestingly, in their antibacterial activity [17], as well as their sustained release [18] and osteo-integration [19]. Therefore, in the present work, we have synthesized chitosan-mediated silver nanoparticles (AgCH-NPs) with the aim of incorporating them into a PLA-OLA SMP matrix at different weight ratios, to obtain appropriate formulations with antimicrobial activity for their use as thermoplastic medical materials. The microstructural, morphological and antibacterial properties of synthesized AgCH-NPs as well as obtained nanocomposites were studied in a previous work [20]. 
The obtained balanced mechanical properties (ductility and toughness), together with the bactericidal effect and the non-toxicity of the AgCH-NP synthesis method, led us to examine their potential application as functional smart materials of interest in biomedicine. Consequently, to that end, the present work explores, in detail, the thermal, dynamo-mechanical and shape memory properties, as well as the antifungal activity, of the developed nanocomposites. The resulting shape memory polymeric systems are expected to provide shape recovery of the permanent shape and, at the same time, wider biocidal activity, broadening the application of PLA in the field of medicine.

\section{Materials and Methods}

\subsection{Materials}

Chitosan from shrimp shells (deacetylation degree $>75 \%)$ and silver nitrate $\left(\mathrm{AgNO}_{3}\right)$ were purchased from Sigma-Aldrich (St. Quentin Fallavier, France). Sodium hydroxide and acetic acid were purchased from Fluka (Seelze, Germany). Lactic acid oligomer (OLA) (Glyplas OLA8, ester content $>99 \%$, density $1.11 \mathrm{~g} / \mathrm{cm}^{3}$, viscosity $22.5 \mathrm{mPa} \cdot \mathrm{s}$, molecular weight $1100 \mathrm{~g} / \mathrm{mol}$ ) was a gift from Condensia Quimica SA (Barcelona, Spain) and polylactic acid (PLA3051D, 3\% of D-lactic acid monomer, molecular weight $142 \times 10^{4} \mathrm{~g} / \mathrm{mol}$, density $1.24 \mathrm{~g} / \mathrm{cm}^{3}$ ) was provided by NatureWorks ${ }^{\circledR}$ (Naarden, The Netherlands).

\subsection{Processing of Shape Memory Plasticized PLA/OLA Nanocomposites}

Chitosan-mediated silver nanoparticles (AgCH-NPs) were synthesized following a previously reported protocol [21,22], obtaining spherical nanoparticles with diameters about $8 \mathrm{~nm}$ [20]. Nanocomposites of PLA-OLA containing the synthesized AgCH-NPs were obtained at $180{ }^{\circ} \mathrm{C}$ with a rotation speed of $100 \mathrm{rpm}$, in a microextruder equipped with two twin conical co-rotating screws (Thermo Scientific, MiniLab Haake Rheomex CTW5, Karlsruhe, Germany, $7 \mathrm{~cm}^{3}$ capacity). Firstly, PLA was added to the MiniLab and after $2 \mathrm{~min}$, when it had reached the melt state, OLA and $\mathrm{AgCH}-\mathrm{NPs}$ were loaded and mixed for 1 more minute (total mixing/residence PLA time of $3 \mathrm{~min}$ ). Obtained blends were compression molded at $180{ }^{\circ} \mathrm{C}$ in a hot press (Collin P-200-P, Maitenbeth, Germany); after $1 \mathrm{~min}$, to ensure melting, materials were subjected to $5 \mathrm{MPa}$ for $1 \mathrm{~min}$ and subsequently cooled down to room temperature while retaining the pressure for a further $1 \mathrm{~min}$. All the materials were dried previous to their processing, and the amounts of polymer (PLA), plasticizer (OLA) and nanoparticles (AgCH-NPs) were calculated in order to obtain nanocomposites with approximately 0.5 , 1 and 3 wt. $\%$ of AgCH-NPs with respect to the PLA amount.

\subsection{Characterization Techniques}

Viscoelastic measurements of the pure PLA-OLA matrix and nanocomposites were carried out in a DMA/SDTA861e Dynamic Mechanical analyzer (Mettler-Toledo, Greifensee, Switzerland). Dynamo-mechanical thermal analyses (DMTA) were carried out from -60 to $120^{\circ} \mathrm{C}$ with isothermal steps of $5{ }^{\circ} \mathrm{C}$, in the range of $0.1-1 \mathrm{~Hz}$ at 3 steps per decade $(0.1,0.5$ and $1 \mathrm{~Hz})$. Samples with $4 \mathrm{~mm}$ width and $\sim 100 \mu \mathrm{m}$ of average thickness were measured in tensile mode with $10 \mathrm{~mm}$ of effective length between clamps. Strain amplitude was kept constant at $15 \mu \mathrm{m}$. Analyses were performed at least thrice per sample and the average was taken as representative values. Storage and Loss moduli, and Tangent Delta were recorded as a function of temperature and time, and glass transition temperatures ( $T_{\text {gDMTA }}$ ) were calculated as the maximum in Tangent Delta peak. Shape memory properties were quantified in cyclic-thermomechanical tensile tests consisting on a heating-stretching-cooling protocol implemented in a Q800 dynamo mechanical analyzer (TA Instruments, New Castle, DE, USA). Each single cycle included programming the temporary shape and recovering the permanent shape, as follows: (1) programming step-a temporary fixed shape was created under strain-controlled conditions. The sample was first heated up and equilibrated at $45{ }^{\circ} \mathrm{C}$ (a useful temperature for biomedical applications) and stretched to a maximum strain of $50 \%$ by applying a force ramp of 
$0.2 \mathrm{MPa} / \mathrm{min}$. Then, the sample was cooled down and equilibrated at $10{ }^{\circ} \mathrm{C}$ and maintained while the stress was released to zero at $0.5 \mathrm{MPa} / \mathrm{min}$, to fix the temporary shape; (2) recovery step-once the stress was released, the sample was heated again up to $45^{\circ} \mathrm{C}$ at $3{ }^{\circ} \mathrm{C} / \mathrm{min}$ to recover the permanent shape. Then, a subsequent cycle was started and the protocol was repeated four times. Strain fixity ratio $\left(R_{f}\right)$ represents the ability to fix the mechanical deformation $\left(\varepsilon_{\mathrm{m}}\right)$ applied in the programming step; strain recovery ratio $\left(R_{r}\right)$ represents the ability of the material to memorize/recover the permanent shape after the programming step. Both were quantified with the following equations [23-25]:

$$
\begin{gathered}
\mathrm{R}_{\mathrm{f}}(\mathrm{N}) \%=\left(\varepsilon_{\mathrm{u}}(\mathrm{N}) /\left(\varepsilon_{\mathrm{m}}(\mathrm{N})\right) \times 100\right. \\
\mathrm{R}_{\mathrm{r}}(\mathrm{N}) \%=\left(\left(\varepsilon_{\mathrm{m}}(\mathrm{N})-\varepsilon_{\mathrm{f}}(\mathrm{N})\right) /\left(\varepsilon_{\mathrm{m}}(\mathrm{N})-\varepsilon_{\mathrm{f}}(\mathrm{N}-1)\right)\right) \times 100
\end{gathered}
$$

where $\varepsilon_{\mathrm{m}}$ is the maximum strain after cooling and before unloading the sample and $\varepsilon_{\mathrm{u}}$ is the fixed strain after unloading at $10{ }^{\circ} \mathrm{C}$ and in the $\mathrm{N}^{\text {th }}$ cycle during the programming step. $\varepsilon_{\mathrm{f}}$ is the residual strain of the sample after the recovery step in the $\mathrm{N}^{\text {th }}$ cycle. The shape memory temperature profiles were selected based on the results obtained from the DMTA analysis at $1 \mathrm{~Hz}$, and taking into account the fact that potential active medical devices are recommended to be activated in the range of $40-55{ }^{\circ} \mathrm{C}$, a close range to physiological temperatures, which is not harmful for body tissues and avoids premature activation at room temperature [1].

The antimicrobial properties of the nanocomposites were determined against Candida parapsilosis (C. parapsilosis, ATCC 22019) fungi, following the E2149-13a standard method of the American Society for Testing and Materials (ASTM) [26]. Briefly, each nanocomposite was placed into a sterile falcon tube, filled with $10 \mathrm{~mL}$ of the fungi suspension (ca. $10^{5}$ colony forming units (CFU)/mL) and shaken at $150 \mathrm{rpm}$ at room temperature for $24 \mathrm{~h}$. Fungi concentrations at time 0 and after $24 \mathrm{~h}$ were calculated by the plate count method after a 48 -h incubation period. Falcon tubes containing only the inoculum and neat, plasticized PLA were also used as control experiments.

\section{Results}

\subsection{Glass Transition Temperature, Activation Energy and Crystallinity of the Systems}

Regarding the shape memory effect in PLA-based materials, glass transition temperature can be used as the transition temperature of SMPs. Therefore, in order to better understand the shape memory behavior of the developed materials prior to studying their shape memory response, an insight into the effect of the addition of both OLA and AgCH-NPs in terms of the glass transition temperature is essential. In order to characterize the motions of pure PLA/OLA matrix on both crystalline and amorphous regions of the nanocomposites, dynamic mechanical measurements were carried out at multi-frequency temperature sweep mode at three different frequencies. The neat PLA matrix was also characterized for comparison purposes in order to better understand the transitions obtained with the incorporation of OLA. Figure 1 shows the temperature dependence of the storage modulus, $\mathrm{E}^{\prime}$, the loss tangent, $\tan \delta$, and the loss modulus, $\mathrm{E}^{\prime \prime}$, for neat PLA and PLA/OLA at three different frequencies.

Figure 1d (PLA/OLA loss modulus) displays the existence of several transitions that fall into three main absorption regions from -30 to 10,20 to 60 and 60 to $110{ }^{\circ} \mathrm{C}$ that have been labeled as $\beta$ relaxation, $\alpha$ relaxation and cold crystallization region (cc), respectively. The sharp $\alpha$ peak, centered at around $40{ }^{\circ} \mathrm{C}$ in $\tan \delta$ (Figure $1 \mathrm{~b}$ ), is accompanied by a sharp decrease in the storage modulus $\left(E^{\prime}\right)$ and corresponds to the segmental relaxation associated to the glass transition (micro-Brownian motions of long chain segments in the amorphous phase of the matrix). At temperatures below $\mathrm{T}_{\mathrm{g}}$, secondary relaxation processes ( $\beta$ transitions) are appreciated, as broad shallow peaks result from the movements of localized groups of backbone atoms in the amorphous phase due to an increase in free volume with temperature. After $\mathrm{T}_{\mathrm{g}}$ relaxation, a slight increase in $\mathrm{E}^{\prime}$ and $\mathrm{E}^{\prime \prime}$ is accompanied with a transition peak in $\tan \delta$, which is attributed to cold crystallization processes. As occurs with PLA/OLA [27], in PLA three distinct regions can be differentiated. Apparently, the $\beta$ transitions due 
to secondary relaxation processes seem not to be highly affected, while glass transition relaxation is clearly diminished, probably in association with the increase in free volume between chains due to the plasticizing effect of OLA. As expected, an increase in the frequency produces a shift to higher temperatures of the transitions, which is in line with results from the literature [28].

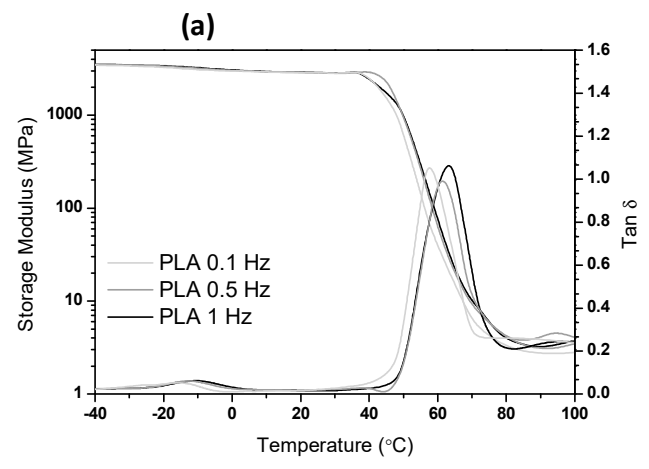

(c)

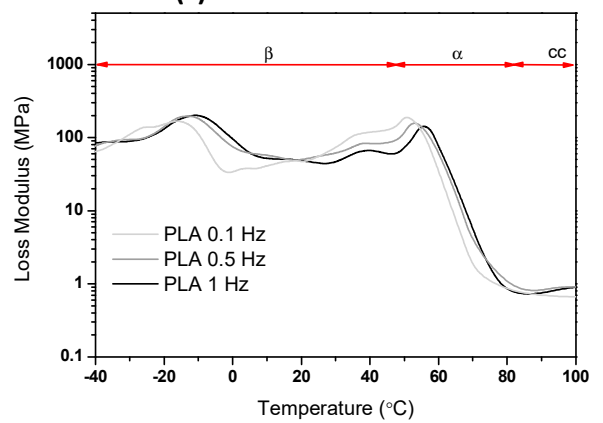

(b)

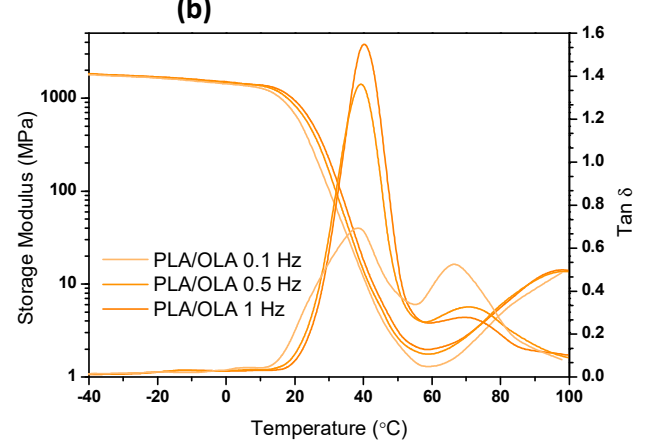

(d)

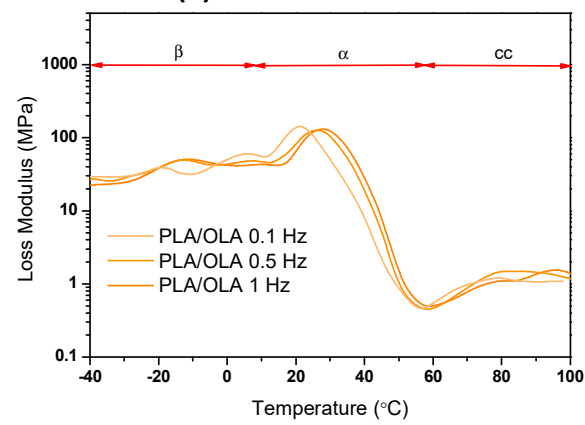

Figure 1. Temperature dependence of (a) poly (lactic acid) (PLA) and (c) PLA/lactic acid oligomer (OLA) storage modulus $\left(E^{\prime}\right)$ and loss tangent $(\tan \delta)$ and (b) PLA and (d) PLA/OLA loss modulus (E') at different frequencies $(0.1,1$ and $3 \mathrm{~Hz})$.

Figure 2 shows the temperature dependence of $\tan \delta$ for neat and plasticized PLA and for all the nanocomposites at a frequency of $1 \mathrm{~Hz}$.

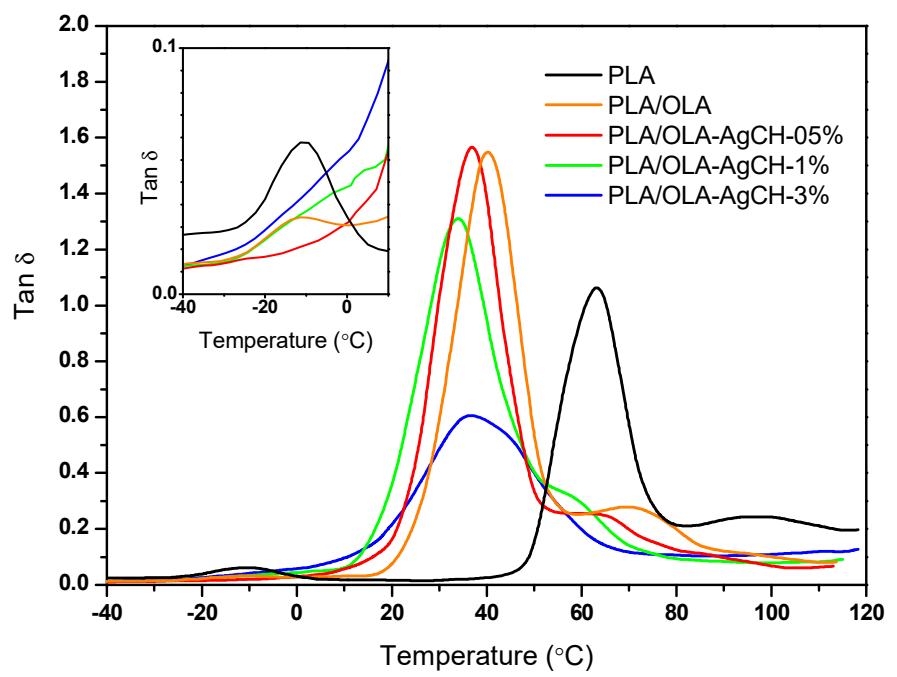

Figure 2. Temperature dependence of PLA, PLA/OLA and PLA/OLA-AgCH nanocomposite delta tangents $(\tan \delta)$ at a frequency of $1 \mathrm{~Hz}$.

As can be seen in Figure 2, the $\alpha$ relaxation corresponding to the glass-rubber transition of samples shifts to a lower temperature with the incorporation of OLA into the PLA matrix. Additionally, 
the $\beta$-relaxation shoulder decreases with both the incorporation of OLA and increases in AgCH-NPs. We observe the same number of absorption peaks for all samples; therefore, it seems that, qualitatively, there are no dramatic changes in the relaxation processes between PLA and PLA/OLA and the nanocomposites at a frequency of $1 \mathrm{~Hz}$. To explore this effect in more detail, we have calculated the characteristic relaxation time of the glass transition relaxation process using the maximum of the delta tangent peak $\left(\mathrm{T}_{\mathrm{g}}\right)$ for the three frequencies investigated by means of the following expression:

$$
\tau\left(\mathrm{T}_{\alpha, \beta, \gamma}\right) \propto(1 / 2 \pi \mathrm{f})
$$

where $\tau$ is the characteristic relaxation time, $\mathrm{T}$ is the temperature at the maximum of the relaxation peak, and $\mathrm{f}$ is the experimental frequency. The dependence of the characteristic relaxation time on temperature, $\tau(\mathrm{T})$, is demonstrated in Figure 3. This dependence can be evaluated using the Arrhenius law, that is:

$$
\tau(\mathrm{T}) \propto \exp \left(E_{a} /\left(\mathrm{k}_{\mathrm{B}} \mathrm{T}\right)\right)
$$

where $E_{a}$ is the activation energy of the corresponding relaxation process. The values of $E_{a}$ for $\alpha$ relaxation process for pure PLA, plasticized PLA/OLA matrix and the nanocomposites together with the values of $T_{g}$ at studied frequencies $(0.1,0.5$ and $1 \mathrm{~Hz})$ are depicted in Table 1 . As previously observed in neat PLA and PLA/OLA, by increasing the test frequency, an increase in $\mathrm{T}_{\mathrm{g}}$ occurs in nanocomposite samples.

\begin{tabular}{|c|c|c|c|}
\hline Sample & $\begin{array}{c}\text { Frequency } \\
{[\mathrm{Hz}]}\end{array}$ & $\begin{array}{l}{ }^{1} \mathrm{~T}_{\mathrm{g}} \\
{\left[{ }^{\circ} \mathrm{C}\right]}\end{array}$ & $\begin{array}{l}{ }^{1} E_{a} \\
{[\mathrm{~kJ}]}\end{array}$ \\
\hline \multirow{3}{*}{ PLA } & 1 & 63 & \multirow{3}{*}{435} \\
\hline & 0.5 & 60 & \\
\hline & 0.1 & 58 & \\
\hline \multirow{3}{*}{ PLA/OLA } & 1 & 41 & \multirow{3}{*}{365} \\
\hline & 0.5 & 38 & \\
\hline & 0.1 & 36 & \\
\hline \multirow{3}{*}{ PLA/OLA-AgCH-0.5\% } & 1 & 37 & \multirow{3}{*}{270} \\
\hline & 0.5 & 34 & \\
\hline & 0.1 & 31 & \\
\hline \multirow{3}{*}{ PLA/OLA-AgCH-1\% } & 1 & 35 & \multirow{3}{*}{215} \\
\hline & 0.5 & 34 & \\
\hline & 0.1 & 27 & \\
\hline \multirow{3}{*}{ PLA/OLA-AgCH-3\% } & 1 & 37 & \multirow{3}{*}{410} \\
\hline & 0.5 & 37 & \\
\hline & 0.1 & 33 & \\
\hline
\end{tabular}

Table 1. Dynamo-mechanical thermal analyses (DMTA) results of $T_{g}$.

${ }^{1}$ Standard errors $( \pm): 1^{\circ} \mathrm{C}$ for temperatures; $5 \mathrm{~kJ}$ for $E_{a}$.

Figure 3 shows the values of $\ln f$ and $\left(1 / \mathrm{T}_{\mathrm{g}}\right)$ for $\mathrm{T}_{\mathrm{g}}$, determined as the maximum in $\tan \delta$. The activation energy related to the glass transition is obtained by multiplying the slopes of the $1 / \mathrm{T}$ vs. $\ln f$ plot with the gas constant, $\mathrm{R}=8.314 \times 10^{-3} \mathrm{~kJ} \mathrm{~mol}^{-1} \mathrm{~K}^{-1}$. The $E_{a}$ values for the glass transition of the neat PLA and PLA/OLA systems are estimated as 435 and $365 \mathrm{~kJ}$, respectively. 


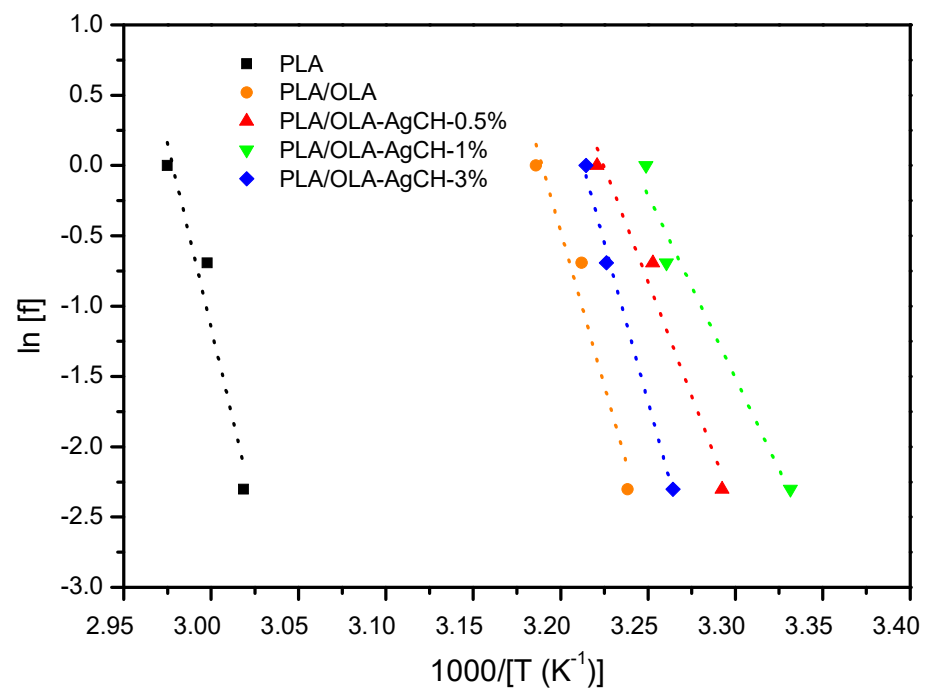

Figure 3. Plot of $\left(1 / \mathrm{T}_{\mathrm{g}}\right)$ vs. $\ln f$ based on $\tan \delta$ peaks for the different systems.

DMTA results evidenced lower glass transition values and $E_{a}$ for PLA/OLA and its nanocomposites in comparison with neat PLA. The addition of OLA shifts the $T_{g}$ towards lower values, evidencing a plasticizing effect. Furthermore, it is noticed that the glass transition temperature decreases with the addition of AgCH-NP content up to $1 \mathrm{wt} . \%$ and then increases with a further increase in nanoparticles (3 wt.\%) being closer to the neat PLA/OLA. This increase, with a high nanoparticle load, can be attributable to the confinement effects of polymer chains between nanoparticles, restricting chain mobility near the surface of AgCH-NPs [29,30]. The activation energy trend agrees with the tendency of $\mathrm{T}_{\mathrm{g}}$; thus, the activation energy decreases for contents up to $1 \mathrm{wt} . \%$ of AgCH-NPs with respect to neat PLA/OLA, while reaching the highest value for $3 \mathrm{wt} . \%$ of $\mathrm{AgCH}-\mathrm{NP}$ load. This fact reflects the fact that high AgCH-NP loads ( $3 \mathrm{wt} . \%$ ) started to hinder the molecular motions of polymeric chains and the fact that higher $E_{a}$ is needed than for neat PLA/OLA.

Underlying thermal mechanisms in triggered semicrystalline SMPs involve the glass transition temperature $\left(T_{g}\right)$ and crystallinity degree. Therefore, as both properties can significantly affect the shape memory performance, it is also worth studying the extent of the effect that the addition of OLA and AgCH-NPs produces over the $\mathrm{T}_{\mathrm{g}}$ and degree of crystallinity of the samples in detail. Table 2 summarizes the $T_{g}$ values obtained from differential scanning calorimetry (DSC), as previously reported [20], and DMTA, as well as the degree of crystallinity. Both $\mathrm{T}_{\mathrm{g}}$ values (from DMTA and DSC), along with numerical differences, follow the same trend. Similar observations have been reported widely in the literature and are usually related to the differences found in the fundamental working principle of each technique as well as in the sample scale size [31,32]. Regardless of those differences, as commented before for $\tan \delta$ and taking neat PLA as reference, the addition of either OLA or AgCH-NP significantly lowers both $\mathrm{T}_{\mathrm{gDSC}}$ and $\mathrm{T}_{\mathrm{gDMTA}}$. As can be deduced from Table 2, the decrease in PLA glass transition is accompanied by an increase in melting enthalpy, suggesting that OLA promotes PLA crystal nucleation, as evidenced through the calculated degree of crystallinity. This is in line with observations done in other PLA plasticized systems and probably occurs due to the lowering of the interfacial surface energy of the plasticized molecules facilitating PLA crystal nucleation [33,34].

Regarding the nanocomposites, an important observation is that amounts of $\mathrm{AgCH}-\mathrm{NPs}$ from 1 to $3 \mathrm{wt} . \%$ induced crystallinity into the PLA/OLA matrix while retaining lower $\mathrm{T}_{\mathrm{gDMTA}}$ and $E_{a}$. This, in principle, can be related to reduced entanglements/interactions occurring among nanoparticles and polymer chains into the amorphous domains, favoring their mobility and therefore reducing the $\mathrm{T}_{\mathrm{g}}$ and $E_{a}$, as previously reported in other nanocomposite systems [35]. 
Table 2. Thermal properties and crystallinity calculated from differential scanning calorimetry (DSC) scan for neat PLA and PLA/OLA and nanocomposites formulations containing AgCH-NPs.

\begin{tabular}{|c|c|c|c|c|c|c|c|c|}
\hline Sample & $\begin{array}{c}{ }^{2} \mathrm{~T}_{\text {gDMTA }} \\
{\left[{ }^{\circ} \mathrm{C}\right]}\end{array}$ & $\begin{array}{c}1,2 \mathrm{~T}_{\text {gDSC }} \\
{\left[{ }^{\circ} \mathrm{C}\right]}\end{array}$ & $\begin{array}{c}1,2 \mathrm{~T}_{\mathrm{cc}} \\
{\left[{ }^{\circ} \mathrm{C}\right]}\end{array}$ & $\begin{array}{l}\Delta \mathbf{H}_{\mathrm{cc}} \\
{[\mathrm{J} / \mathrm{g}]}\end{array}$ & $\begin{array}{c}1,2 \mathrm{~T}_{\mathrm{m}} \\
{\left[{ }^{\circ} \mathrm{C}\right]}\end{array}$ & $\begin{array}{l}\Delta \mathbf{H}_{\mathrm{m}} \\
{[\mathrm{J} / \mathrm{g}]}\end{array}$ & $\begin{array}{c}\Delta \mathbf{H}_{\text {Total }} \\
{[\mathrm{J} / \mathrm{g}]}\end{array}$ & $\begin{array}{c}{ }^{1} \mathrm{X}_{\mathrm{c}-\mathrm{DSC}} \\
{[\%]}\end{array}$ \\
\hline PLA & 63 & 62 & 123 & 2 & 149 & 2 & 0 & - \\
\hline PLA/OLA & 41 & 32 & 88 & 25 & 143 & 27 & 2 & 2.8 \\
\hline $\begin{array}{l}\text { PLA/OLA } \\
\mathrm{AgCH} 0.5 \%\end{array}$ & 37 & 25 & 83 & 27 & 142 & 27 & 0 & 0.0 \\
\hline $\begin{array}{l}\text { PLA/OLA } \\
\text { AgCH1\% }\end{array}$ & 35 & 24 & 76 & 23 & 142 & 29 & 6 & 9.2 \\
\hline $\begin{array}{l}\text { PLA/OLA } \\
\text { AgCH3\% }\end{array}$ & 37 & 50 & 66 & 2 & 142 & 30 & 28 & 38.0 \\
\hline
\end{tabular}

${ }^{1}$ From reference [20]. ${ }^{2}$ Standard errors ( \pm ): $1{ }^{\circ} \mathrm{C}$ for temperatures, $1 \mathrm{~J} / \mathrm{g}$ in $\Delta \mathrm{H}_{\mathrm{m}}$ and $5 \%$ for $\mathbf{X}_{\mathbf{c}}$.

Apart from $\tan \delta$, the storage modulus and loss modulus can give a good insight into the understanding of the shape memory performance. Figure 4 shows the evolution of the storage modulus $\left(\mathrm{E}^{\prime}\right)$ and loss modulus ( $\left.\mathrm{E}^{\prime \prime}\right)$ as a function of temperature. As expected, the addition of OLA decreases the $E^{\prime}$ and $E^{\prime \prime}$ values of the system at low temperatures. The loss modulus width broadens with the increase in AgCH-NP content at the same time that the maximum moves to lower temperatures in comparison to PLA/OLA samples. These results illustrate that molecular mobility is more easily activated for nanocomposites containing $0.5-1 \mathrm{wt} . \%$ of AgCH-NPs in agreement with calculated $E_{a}$.

(a)

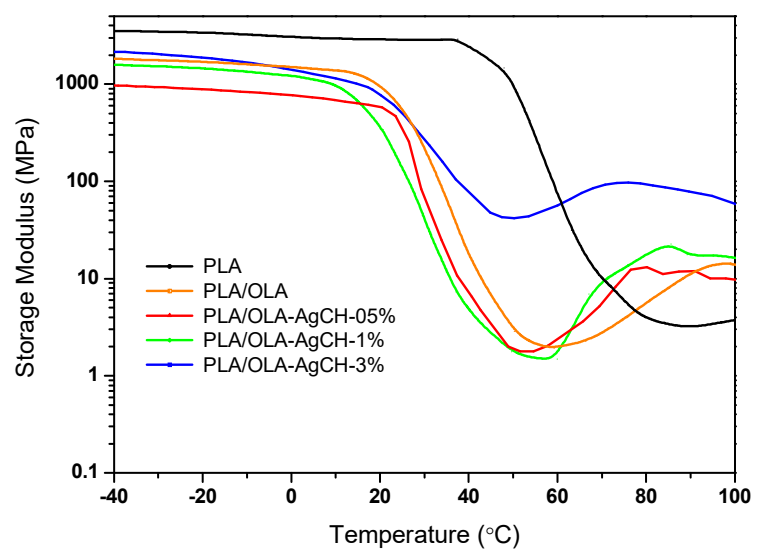

(b)

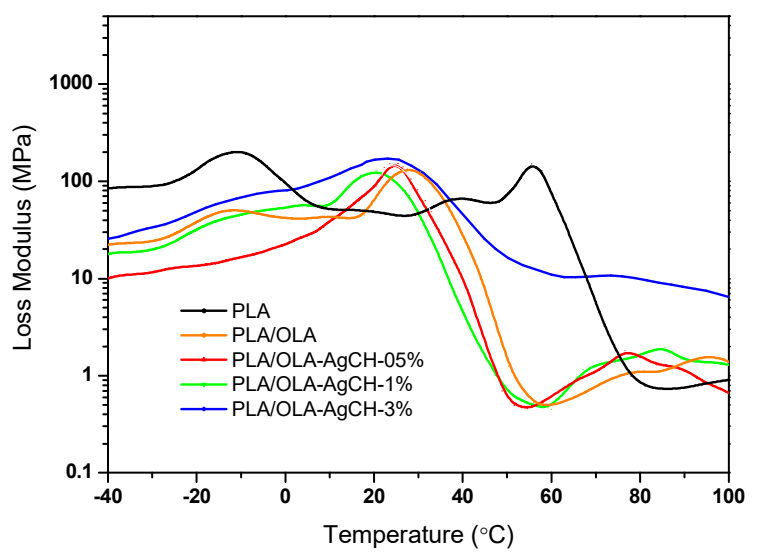

Figure 4. Evolution of (a) storage modulus $\left(E^{\prime}\right)$ and $(\mathbf{b})$ loss modulus $\left(E^{\prime \prime}\right)$ as a function of temperature.

As can be observed in Figure 5, in the glassy state (at $\left.-40{ }^{\circ} \mathrm{C}\right)$, PLA/OLA and its nanocomposites containing 1-3 wt.\% of AgCH-NPs show similar E' values, $1811 \mathrm{MPa}, 1578 \mathrm{MPa}$ and $2134 \mathrm{MPa}$ for neat PLA/OLA, 1 and $3 \mathrm{wt}$.\% for AgCH-NP nanocomposites, respectively, while, for a lower amount of filler (0.5 wt.\%), a slight decrease in the modulus occurs (966 MPa), which can be related to the absence of crystallinity in this sample. At ambient temperature $\left(25^{\circ} \mathrm{C}\right)$, the stiffness starts to display a reduction as all the samples are close to glass transition temperature and, upon increasing the temperature to $45^{\circ} \mathrm{C}$, the stiffness displays a drastic reduction, reaching values of $\sim 4 \mathrm{MPa}$ for nanocomposites containing $0.5-1 \mathrm{wt} . \%$ of AgCH-NPs and $~ 7 \mathrm{MPa}$ for neat PLA/OLA. Interestingly, the addition of 3 wt.\% of AgCH-NPs leads to a substantially higher reinforcement of the $\mathrm{E}^{\prime}$ moduli compared to neat PLA/OLA. Moreover, this reinforcement effect is retained despite the increase in the temperature and the cold crystallization. 


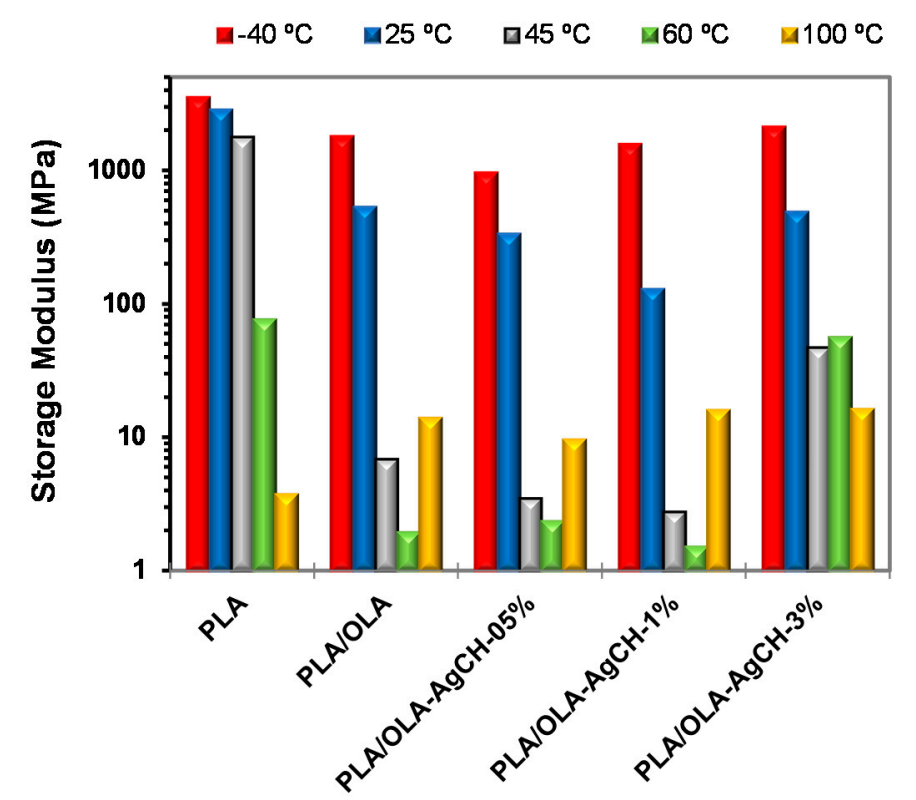

Figure 5. Storage Modulus, $E^{\prime}$, at different temperatures.

\subsection{Shape Memory Properties; Thermal Activation}

As mentioned before, nowadays, PLA represents one of the most exceptional polymers in the biomedicine field for controlled drug delivery and tissue engineering. Nevertheless, in spite of its benefits, its inherent brittleness has been limiting its use. In this sense, the shape memory effect of neat PLA has been theorized by many research groups [36-38]; however, it was not observed due to its brittleness at room temperature. Therefore, in order to avoid the brittle fracture of the material, mainly polyurethanes (TPU) and poly ( $\varepsilon$-caprolactone) polyester, have become common choices for blending or copolymerizing with PLA to create useful and flexible SMP [39,40]. Our research approach using lactic acid oligomer (OLA) as plasticizer ensures the compatibility of the blend and contributes to improving the ductility of the PLA, decreasing the glass transition to temperatures useful for biomedical applications. Thus, considering the results obtained in the DMTA analysis for the addition of AgCH-NPs, and to fulfill the requirements for further applications in biomedicine-in terms of facilitating the manipulation, storage and implantation of a possible device-a temperature of $45^{\circ} \mathrm{C}$ has been selected for the activation of the shape recovery [1]. As previously explained in the experimental section, the shape memory properties were quantified through shape recovery $\left(R_{r}\right)$ and shape fixity $\left(R_{f}\right)$ ratios in three consecutive thermomechanical cycles in a DMTA. Temporary shape was programmed at $45^{\circ} \mathrm{C}$ ( $\mathrm{T}_{\text {high }}>\mathrm{T}_{\text {gDMTA }}$ determined from the maximum in the tan $\delta$ curves) by elongating the sample until it reached $50 \%$ strain, then it was fixed at $10{ }^{\circ} \mathrm{C}\left(\mathrm{T}_{\text {low }}<\mathrm{T}_{\mathrm{gDMTA}}\right)$ under constant stress. After removing the load, recovery was performed at $45^{\circ} \mathrm{C}$. Figure 6 shows the evolution of stress and strain as a function of time and temperature for neat PLA/OLA and its AgCH-NP nanocomposites. Table 3 collects the calculated numerical values for $R_{r}$ and $R_{f}$ as well as stress at maximum deformation. 

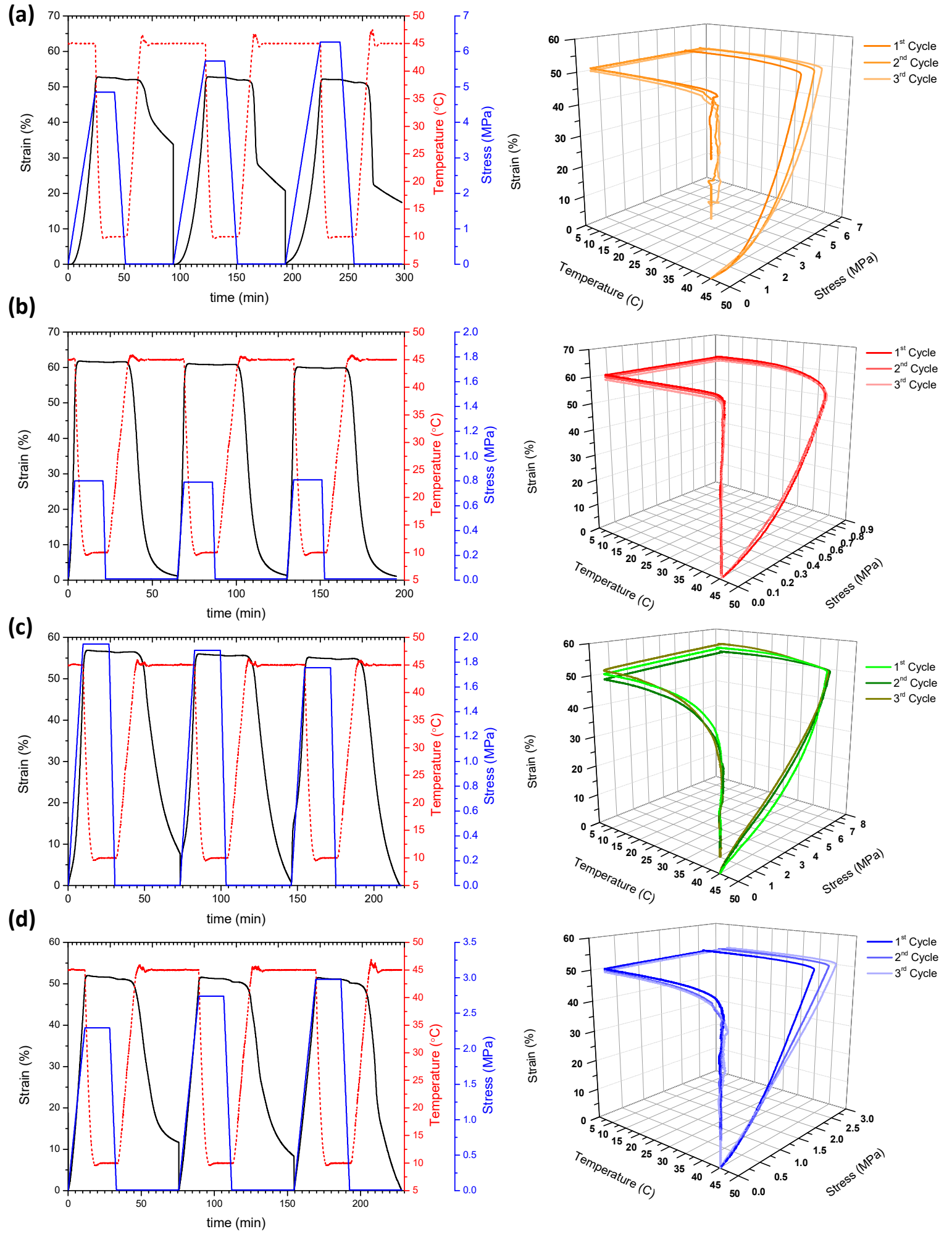

Figure 6. $2 \mathrm{D}$ and $3 \mathrm{D}$ thermo-mechanical cycles performed at $45{ }^{\circ} \mathrm{C}$ for (a) neat PLA/OLA and its nanocomposites containing (b) $0.5 \mathrm{wt} . \%$ of AgCH-NPs, (c) $1 \mathrm{wt} . \%$ of AgCH-NPs and (d) $3 \mathrm{wt} . \%$ of AgCH-NPs. 
Table 3. Strain recovery, strain fixity and stress at maximum strain values for each shape memory cycle.

\begin{tabular}{ccccc}
\hline Sample & $\begin{array}{c}\text { Cycle } \\
{\left[\mathbf{N}^{\circ}\right]}\end{array}$ & $\begin{array}{c}\mathbf{R}_{\mathbf{r}} \mathbf{( N )} \\
{[\%]}\end{array}$ & $\begin{array}{c}\mathbf{R}_{\mathbf{f}} \mathbf{( N )} \\
{[\%]}\end{array}$ & $\begin{array}{c}\text { Stress at Max. Strain } \\
{[\mathbf{M P a}]}\end{array}$ \\
\hline \multirow{3}{*}{ PLA/OLA } & 1 & 36 & 99 & 4.9 \\
& 2 & 61 & 99 & 5.6 \\
& 3 & 67 & 99 & 6.0 \\
\hline \multirow{2}{*}{ PLA/OLA-AgCH-0.5\% } & 1 & 98 & 100 & 0.8 \\
& 2 & 98 & 100 & 0.8 \\
& 3 & 98 & 100 & 0.8 \\
\hline \multirow{3}{*}{ PLA/OLA-AgCH-1\% } & 1 & 86 & 100 & 1.9 \\
& 2 & 99 & 100 & 1.9 \\
& 3 & 100 & 100 & 1.7 \\
\hline \multirow{2}{*}{ PLA/OLA-AgCH-3\% } & 1 & 77 & 99 & 2.3 \\
& 2 & 84 & 99 & 2.7 \\
& 3 & 100 & 99 & 3.0 \\
\hline
\end{tabular}

Under the conditions used, shape fixity ratios remained constant for all the samples and close to unity $\left(\mathrm{R}_{\mathrm{f}}=99-100 \%\right)$, without the appreciable influence of the AgCH-NP content or the number of cycles. Conversely, shape recovery ratios $\left(R_{r}\right)$ were higher for all the nanocomposites compared to neat PLA/OLA, which showed an incomplete shape recovery (lower than $50 \%$ for the first cycle). Figure 7 details the graphical evolution of shape memory parameters $\left(\mathrm{R}_{\mathrm{f}}\right.$ and $\left.\mathrm{R}_{\mathrm{r}}\right)$ as a function of AgCH-NP content, complementing the information in Table 3. By incorporating AgCH-NPs into PLA/OLA, the recovery ratio in the first cycle improves, reaching the optimum at $0.5 \mathrm{wt} . \%$ of AgCH-NPs with an $\mathrm{R}_{\mathrm{r}}$ of $98 \%$ and then, despite the better performance of the nanocomposites, a reduction in $\mathrm{R}_{\mathrm{r}}$ to $86 \%$ and $77 \%$ was observed for samples with 1 and $3 \mathrm{wt} . \%$ of AgCH-NP content, respectively. According to DMTA results, these lower $\mathrm{R}_{\mathrm{r}}$ values for the first cycle, with increasing $\mathrm{AgCH}-\mathrm{NP}$ content, might be attributed to the enhancement of crystallinity and the more limited movement of amorphous polymer chains. Shape recovery is driven by the entropic stresses in the amorphous phase and, as shown in Figure 2, the magnitude of the $\tan \delta$ transition decreases with increasing nanoparticle content, indicating that less mobile units are involved in the relaxation process and thus higher hysteresis occurs. With the increasing cycle number in the shape memory test, $R_{\mathrm{r}}$ shows an increasing trend, stabilizing near 100\% after the second or third cycle for 1 and $3 \mathrm{wt} . \%$ of $\mathrm{AgCH}-\mathrm{NPs}$ containing samples. Besides this training effect of $R_{r}$ with cycles, strain recovery showed a strong dependence on nanoparticle content, whereas this dependence seems negligible for strain fixity performance.

a)

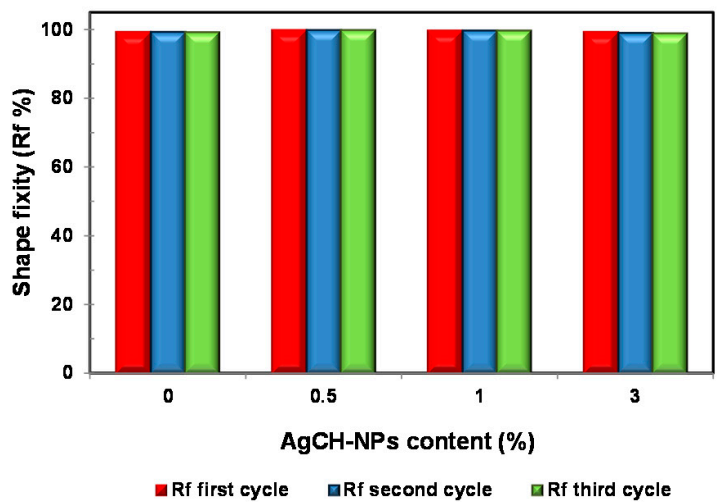

b)

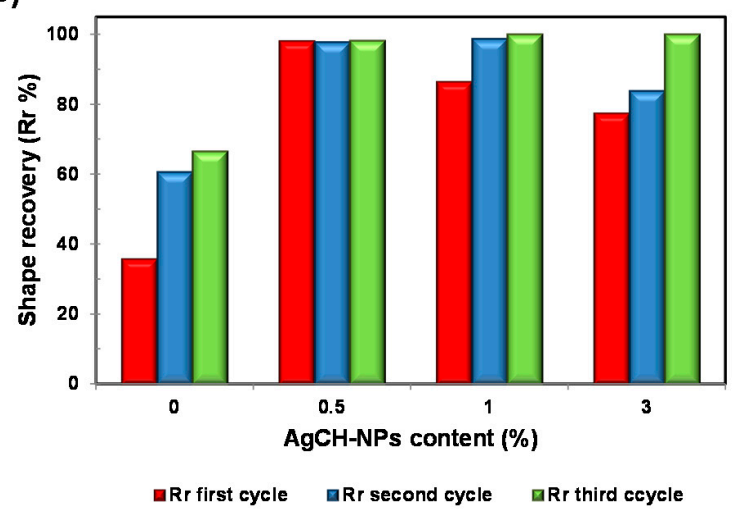

Figure 7. Shape fixity ratio (a) and shape recovery ratio (b) characteristic values for neat PLA/OLA and its nanocomposites containing 0.5, 1 and $3 \mathrm{wt} . \%$ of AgCH-NPs. 
The stress at maximum deformation (Table 3 ) is lower for all the nanocomposites compared to pure PLA/OLA. This fact is in accordance with the effect of the AgCH-NP addition over the mechanical properties of PLA/OLA matrices reported in our previous work [20].

Figure 8 shows the evolution over time of the normalized strain during the recovery stage of the first cycle of the shape memory, for neat PLA/OLA and its nanocomposites at $45^{\circ} \mathrm{C}$. It could be seen that, for the same recovered strain (i.e., $80 \%$ of strain, thus $20 \%$ of strain recovered), all the nanocomposites presented faster recovery than the neat PLA/OLA, with the fastest being the nanocomposite containing $1 \mathrm{wt} . \%$ of AgCH-NPs. All the materials presented their $\mathrm{T}_{\mathrm{g}}$ at lower temperatures than the set for recovery $\left(45^{\circ} \mathrm{C}\right)$ and, in spite of similar glass transitions to neat PLA/OLA and $3 \mathrm{wt} . \%$ of AgCH-NP samples, the recovery of the latter is faster. Thus, it seems that the presence of AgCH-NPs provides an extra force to the PLA/OLA matrix, helping the molecular chains to return to their original configuration.

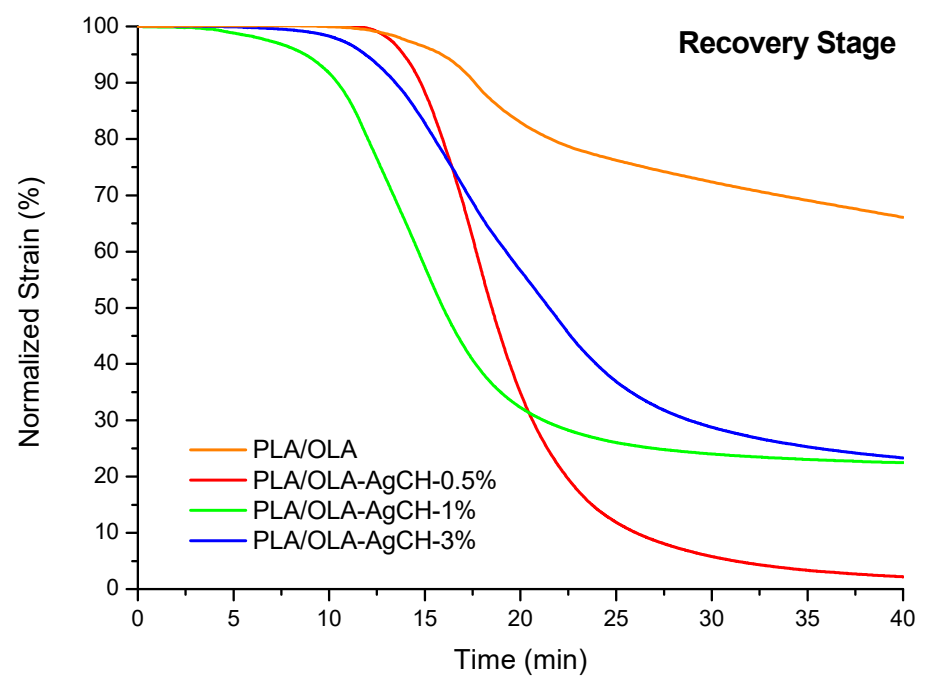

Figure 8. Normalized recovered strain with time for neat PLA/OLA and its nanocomposites containing $0.5,1$ and 3 wt. $\%$ of AgCH-NPs.

These results demonstrate that the better overall performance of the nanocomposites might also be due to improved local heating and more efficient heat transfer during heating, which leads to less dissipation of energy, a faster response and higher shape recovery.

\subsection{Antifungal Activity}

In a previous work, these nanocomposites were tested against Gram-positive Staphylococcus aureus and Gram-negative Escherichia coli bacteria, showing that they exhibited antibacterial activities due to the dual combination action of silver ions and the cationic chitosan [20]. In this work, we extended our analysis of their antimicrobial behavior, testing them against $C$. parasilopsis fungi. Fungi present different membrane structures than bacteria; fungal walls are composed of chitin and polysaccharides, while bacteria are mainly made of peptidoglycans, lipoproteins and others. Therefore, the antibacterial activity of nanocomposites can be different than the antifungal effectivity.

The antifungal activity of nanocomposites was tested by the ASTM standard method [26]. Table 4 summarizes the antifungal activity represented as the percentage of fungi killed, which was calculated by the difference between the CFU after contact with control substrates (PLA/OLA and none), $A$, and $\mathrm{CFU}$ after contact with the polymeric nanocomposites, $B$, following the equation:

$$
\text { Percentage of fungi killed }=(A-B) / A \times 100
$$


Table 4. Killing percentage for C. parapsilosis fungi by nanocomposite samples.

\begin{tabular}{cc}
\hline Sample & Killing Percentage [\%] \\
\hline PLA & - \\
PLA/OLA & - \\
PLA/OLA CH & 90 \\
PLA/OLA-AgCH-0.5\% & 99 \\
PLA/OLA-AgCH-1\% & 99 \\
PLA/OLA-AgCH-3\% & 99 \\
\hline
\end{tabular}

As can be seen, all nanocomposites exhibited significant antifungal activity. It is worth noting that the incorporation of only $0.5 \mathrm{wt} . \%$ of chitosan-mediated silver nanoparticles (AgCH-NPs) was able to kill $99 \%$ of fungi present in the tested suspension in contact with the film.

\section{Conclusions}

In this study, plasticized PLA-based SMP nanocomposites with tailored functionality were prepared with different amounts of chitosan-mediated silver nanoparticles, AgCH-NPs (0.5, 1 and $3 \mathrm{wt.} \%$ ). Nanocomposites were obtained by melt-compounding in a twin-screw extruder, and were subsequently hot pressed. A comprehensive evaluation of the performance of the neat plasticized matrix as well as the nanocomposites was conducted by focusing on their dynamo-mechanical, shape memory and antimicrobial properties. To that end, their dynamic thermo-mechanical and shape memory behavior, as well as antifungal properties, were studied. The plasticizing effect of OLA notably lowers the $\mathrm{T}_{\mathrm{g}}$ value of the neat PLA by at least $30^{\circ} \mathrm{C}$, according to DMTA measurements. In addition, a significant decrease also occurs in the storage and loss modulus at temperatures close to the physiological one of interest. PLA/OLA based nanocomposites showed a complex thermo-mechanical behavior, where the presence of the AgCH-NPs, especially high loads (3 wt.\%), sufficiently affected the crystallinity and thermo-mechanical properties. Importantly, the addition of $0.5-1 \mathrm{wt} . \%$ of nanoparticles into the PLA/OLA matrix slightly reduces the glass transition temperature, while loads of $3 \mathrm{wt} . \%$ hinder the molecular motions of the chains, increasing the $T_{g}$ to values closer to the neat material. Although an increase in the $T_{g}$ and activation energy occurs in the nanocomposite with the highest load, those values are still below the ones of neat PLA/OLA. The presence of AgCH-NPs is responsible for the enhanced crystallinity, the lower glass transition and activation energies, as well as the reinforcement of the storage modulus in the rubbery region $\left(45-100^{\circ} \mathrm{C}\right)$ of the nanocomposites in comparison to the neat matrix. All these facts together are the driving forces for the better overall performance of the nanocomposites in the shape memory tests at the temperature of interest, resulting in higher and faster recovery ratios. In this sense, $\mathrm{AgCH}-\mathrm{NPs}$ seem to provide an extra force to the PLA/OLA matrix to return the original configuration. In addition, the nanocomposites showed excellent antimicrobial effects, which, combined with the enhancement of their shape memory properties, give these materials great potential for performing as substrates with multi-functionality in the biomedical field.

Author Contributions: Conceptualization, D.L., A.S. and S.M.; methodology, D.L., A.S., G.R., M.F.-G., C.E., S.M., A.M.-B., L.P., A.L.; validation, D.L., A.S., L.P. and M.F.-G.; investigation, D.L., A.S., G.R., M.F.-G., C.E., S.M., A.M.-B., A.L., L.P.; writing-original draft preparation, A.S.; writing-review and editing, A.S., D.L., M.F.-G., A.M.-B., L.P.; supervision, D.L.; project administration, D.L. and M.F.-G.; funding acquisition, D.L., L.P. and M.F.-G. All authors have read and agreed to the published version of the manuscript.

Funding: This research was funded by Spanish Ministry of Science and Innovation (AEIMICINN/FEDER); Projects MAT2016-78437-R, MAT2017-88123-P and PCIN-2017-036.

Acknowledgments: A. S. acknowledges her "APOSTD/2018/228" and "PAID-10-19" postdoctoral contracts from the Education, Research, Culture and Sport Council from the Government of Valencia and from the Polytechnic University of Valencia, respectively. C.E. acknowledges the IJCI-2015-26432 contract from MICINN. L.P. acknowledges the Ramon y Cajal (RYC-2014-15595) contract from MICINN.

Conflicts of Interest: The authors declare no conflict of interest. 


\section{References}

1. Yakacki, C.M.; Gall, K. Shape-Memory Polymers for Biomedical Applications. In Shape-Memory Polymers. Advances in Polymer Science Series; Lendlein, A., Ed.; Springer: Berlín/Heidelberg, Germany, 2009; Volume 226, pp. 147-175.

2. Lendlein, A.; Behl, M.; Hiebl, B.; Wischke, C. Shape-memory polymers as a technology platform for biomedical applications. Expert Rev. Med. Devices 2010, 7, 357-379. [CrossRef] [PubMed]

3. Serrano, M.C.; Ameer, G.A. Recent insights into the biomedical applications of shape-memory polymers. Macromol. Biosci. 2012, 12, 1156-1171. [CrossRef] [PubMed]

4. Sabir, M.; Xu, X.; Li, L. A review on biodegradable polymeric materials for bone tissue engineering applications. J. Mater. Sci. 2009, 44, 5713-5724. [CrossRef]

5. Feng, Y.; Guo, J. Biodegradable polydepsipeptides. Int. J. Mol. Sci. 2009, 10, 589-615. [CrossRef]

6. Grijpma, D.W.; Pennings, A.J. (Co)polymers of L-lactide, 2. Mechanical properties. Macromol. Chem. Phys. 1994, 195, 1649-1663. [CrossRef]

7. Liu, H.; Zhang, J. Toughening modification of poly(lactic acid) via melt blending. ACS Symp. Ser. 2012, 1105, $27-46$.

8. Choi, N.-Y.; Kelch, S.; Lendlein, A. Synthesis, Shape-Memory Functionality and Hydrolytical Degradation Studies on Polymer Networks from Poly(rac-lactide)-b-poly(propylene oxide)-b-poly(rac-lactide) dimethacrylates. Adv. Eng. Mater. 2006, 8, 439-445. [CrossRef]

9. Kelch, S.; Choi, N.Y.; Wang, Z.; Lendlein, A. Amorphous, elastic AB copolymer networks from acrylates and poly[(L-lactide)-ran-glycolide]dimetfiacrylates. Adv. Eng. Mater. 2008, 10, 494-502. [CrossRef]

10. Min, C.; Cui, W.; Bei, J.; Wang, S. Effect of comonomer on thermal/mechanical and shape memory property of L-lactide-based shape-memory copolymers. Polym. Adv. Technol. 2007, 18, 299-305. [CrossRef]

11. Yang, J.; Liu, F.; Yang, L.; Li, S.M. Hydrolytic and enzymatic degradation of poly(trimethylene carbonate-co-D,L-lactide) random copolymers with shape memory behavior. Eur. Polym. J. 2010, 46, 783-791. [CrossRef]

12. Liu, C.; Mather, P.T. Thermomechanical characterization of blends of poly(vinyl acetate) with semicrystalline polymers for shape memory applications. In Proceedings of the 61st Annual Technical Conference ANTEC 2003, Nashville, TN, USA, 4-8 May 2003; pp. 1962-1966.

13. Wang, L.S.; Chen, H.C.; Xiong, Z.C.; Pang, X.B.; Xiong, C.D. Novel degradable compound shape-memory-polymer blend: Mechanical and shape-memory properties. Mater. Lett. 2010, 64, 284-286. [CrossRef]

14. Sessini, V.; Navarro-Baena, I.; Arrieta, M.P.; Dominici, F.; López, D.; Torre, L.; Kenny, J.M.; Dubois, P.; Raquez, J.M.; Peponi, L. Effect of the addition of polyester-grafted-cellulose nanocrystals on the shape memory properties of biodegradable PLA/PCL nanocomposites. Polym. Degrad. Stab. 2018, 152, 126-138. [CrossRef]

15. Leonés, A.; Sonseca, A.; López, D.; Fiori, S.; Peponi, L. Shape memory effect on electrospun PLA-based fibers tailoring their thermal response. Eur. Polym. J. 2019, 117, 217-226. [CrossRef]

16. Choi, A.H.; Ben-Nissan, B.; Matinlinna, J.P.; Conway, R.C. Current perspectives: Calcium phosphate nanocoatings and nanocomposite coatings in dentistry. J. Dent. Res. 2013, 92, 853-859. [CrossRef]

17. Beyth, N.; Farah, S.; Domb, A.J.; Weiss, E.I. Antibacterial dental resin composites. React. Funct. Polym. 2014, 75, 81-88. [CrossRef]

18. Hook, E.R.; Owen, O.J.; Bellis, C.A.; Holder, J.A.; O’Sullivan, D.J.; Barbour, M.E. Development of a novel antimicrobial-releasing glass ionomer cement functionalized with chlorhexidine hexametaphosphate nanoparticles. J. Nanobiotechnol. 2014, 12,1-9. [CrossRef]

19. Chien, C.Y.; Liu, T.Y.; Kuo, W.H.; Wang, M.J.; Tsai, W.B. Dopamine-assisted immobilization of hydroxyapatite nanoparticles and RGD peptides to improve the osteoconductivity of titanium. J. Biomed. Mater. Res. Part A 2013, 101 A, 740-747. [CrossRef]

20. Sonseca, A.; Madani, S.; Rodríguez, G.; Hevilla, V.; Echeverría, C.; Fernández-García, M.; Muñoz-Bonilla, A.; Charef, N.; López, D. Multifunctional PLA blends containing chitosan mediated silver nanoparticles: Thermal, mechanical, antibacterial, and degradation properties. Nanomaterials 2020, 10, 22. [CrossRef]

21. Wei, D.; Sun, W.; Qian, W.; Ye, Y.; Ma, X. The synthesis of chitosan-based silver nanoparticles and their antibacterial activity. Carbohydr. Res. 2009, 344, 2375-2382. [CrossRef] 
22. Kalaivani, R.; Maruthupandy, M.; Muneeswaran, T.; Hameedha Beevi, A.; Anand, M.; Ramakritinan, C.M.; Kumaraguru, A.K. Synthesis of chitosan mediated silver nanoparticles (Ag NPs) for potential antimicrobial applications. Front. Lab. Med. 2018, 2, 30-35. [CrossRef]

23. Behl, M.; Lendlein, A. Shape-memory polymers. Mater. Today 2007, 10, 20-28. [CrossRef]

24. Wagermaier, W.; Kratz, K.; Heuchel, M.; Lendlein, A. Characterization Methods for Shape-Memory Polymers. Adv. Polym. Sci. 2010, 226, 97-145.

25. Ratna, D.; Karger-Kocsis, J. Recent advances in shape memory polymers and composites: A review. J. Mater. Sci. 2008, 43, 254-269. [CrossRef]

26. ASTM E2149-13a. Standard Test Method for Determining the Antimicrobial Activity of Antimicrobial Agents under Dynamic Contact Conditions; ASTM International: West Conshohocken, PA, USA, 2013.

27. Shmool, T.A.; Zeitler, J.A. Insights into the structural dynamics of poly lactic-: Co-glycolic acid at terahertz frequencies. Polym. Chem. 2019, 10, 351-361. [CrossRef]

28. Frequency Dependence of Glass Transition Temperatures. Applications Notes Library, TA Instruments, Thermal Analysis, Rheology, TA423. Available online: https://www.tainstruments.com/applications-librarysearch/ (accessed on 10 May 2020).

29. Kuljanin-Jakovljević, J.; Stojanović, Z.; Nedeljković, J.M. Influence of CdS-filler on the thermal properties of poly(methyl methacrylate). J. Mater. Sci. 2006, 41, 5014-5016. [CrossRef]

30. Liu, X.; Wang, T.; Chow, L.C.; Yang, M.; Mitchell, J.W. Effects of Inorganic Fillers on the Thermal and Mechanical Properties of Poly(lactic acid). Int. J. Polym. Sci. 2014, 2014, 827028. [CrossRef]

31. Xu, J.; Shi, W.; Pang, W. Synthesis and shape memory effects of Si-O-Si cross-linked hybrid polyurethanes. Polymer (Guildf) 2006, 47, 457-465. [CrossRef]

32. Kalichevsky, M.T.; Jaroszkiewicz, E.M.; Ablett, S.; Blanshard, J.M.V.; Lillford, P.J. The glass transition of amylopectin measured by DSC, DMTA and NMR. Carbohydr. Polym. 1992, 18, 77-88. [CrossRef]

33. Seo, M.K.; Lee, J.R.; Park, S.J. Crystallization kinetics and interfacial behaviors of polypropylene composites reinforced with multi-walled carbon nanotubes. Mater. Sci. Eng. A 2005, 404, 79-84. [CrossRef]

34. Sheth, M.; Kumar, R.A.; Dave, V. Biodegradable Polymer Blends of Poly (lactic acid) and Poly (ethylene glycol). J. Appl. Polymer Sci. 2008, 66, 1495-1505. [CrossRef]

35. Patidar, D.; Agrawal, S.; Saxena, N.S. Glass transition activation energy of CdS/PMMA nano-composite and its dependence on composition of CdS nano-particles. J. Therm. Anal. Calorim. 2011, 106, 921-925. [CrossRef]

36. Zhang, W.; Chen, L.; Zhang, Y. Surprising shape-memory effect of polylactide resulted from toughening by polyamide elastomer. Polymer (Guildf) 2009, 50, 1311-1315. [CrossRef]

37. Zhang, H.; Wang, H.; Zhong, W.; Du, Q. A novel type of shape memory polymer blend and the shape memory mechanism. Polymer (Guildf) 2009, 50, 1596-1601. [CrossRef]

38. Lai, S.M.; Lan, Y.C. Shape memory properties of melt-blended polylactic acid (PLA)/thermoplastic polyurethane (TPU) bio-based blends. J. Polym. Res. 2013, 20, 2-9. [CrossRef]

39. Peponi, L.; Navarro-Baena, I.; Sonseca, A.; Gimenez, E.; Marcos-Fernandez, A.; Kenny, J.M. Synthesis and characterization of PCL-PLLA polyurethane with shape memory behavior. Eur. Polym. J. 2013, 49, 893-903. [CrossRef]

40. Peponi, L.; Sessini, V.; Arrieta, M.P.; Navarro-Baena, I.; Sonseca, A.; Dominici, F.; Gimenez, E.; Torre, L.; Tercjak, A.; López, D.; et al. Thermally-activated shape memory effect on biodegradable nanocomposites based on PLA/PCL blend reinforced with hydroxyapatite. Polym. Degrad. Stab. 2018, 151, 36-51. [CrossRef]

(C) 2020 by the authors. Licensee MDPI, Basel, Switzerland. This article is an open access article distributed under the terms and conditions of the Creative Commons Attribution (CC BY) license (http://creativecommons.org/licenses/by/4.0/). 